\title{
Interactions among vegetation and ozone, water and nitrogen fluxes in a coastal Mediterranean maquis ecosystem
}

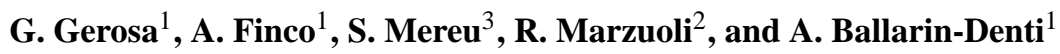 \\ ${ }^{1}$ Dip. to di Matematica e Fisica, Università Cattolica del S.C., via Musei 41, 25121 Brescia, Italy \\ ${ }^{2}$ CRINES, via Galilei 2, Curno, Italy \\ ${ }^{3}$ Dip. to di Biologia Vegetale, Università La Sapienza, via Fermi 1, Rome, Italy
}

Received: 3 December 2008 - Published in Biogeosciences Discuss.: 29 January 2009

Revised: 28 April 2009 - Accepted: 11 August 2009 - Published: 26 August 2009

\begin{abstract}
Ozone, water and energy fluxes were measured over a Mediterranean maquis ecosystem from 5 May until 31 July 2007 by means of the eddy covariance technique. Additional measurements of $\mathrm{NO}_{\mathrm{x}}$ fluxes were performed by the aerodynamic gradient technique. Stomatal ozone fluxes were obtained from water fluxes by a Dry Deposition Inferential Method based on a big leaf concept.

The maquis ecosystem acted as a net sink for ozone. The different water availability between late spring and summer was the major cause of the changes observed in stomatal fluxes, which decreased, together with evapotranspiration, when the season became drier.

$\mathrm{NO}_{\mathrm{x}}$ concentrations were significantly dependent on the local meteorology. $\mathrm{NO}_{\mathrm{x}}$ fluxes resulted less intense than the ozone fluxes. However an average upward flux of both NO and $\mathrm{NO}_{2}$ was measured.

The non-stomatal pathways of ozone deposition were investigated. A correlation of non-stomatal deposition with air humidity and, in a minor way, with $\mathrm{NO}_{2}$ fluxes was found.

Ozone risk assessment was performed by comparing the exposure and the dose metrics: AOT40 (Accumulated dose over a threshold of $40 \mathrm{ppb}$ ) and $\mathrm{AF}_{s t} 1.6$ (Accumulated stomatal flux of ozone over a threshold of $\left.1.6 \mathrm{nmol} \mathrm{m}^{-2} \mathrm{~s}^{-1}\right)$. AOT40, both at the measurement height and at canopy height was greater than the Critical Level for the protection of forests and semi-natural vegetation $(5000 \mathrm{ppb}$ h) adopted by UN-ECE. Also the $\mathrm{AF}_{s t} 1.6$ value $\left(12.6 \mathrm{mmol} \mathrm{m}^{-2}\right.$ PLA, Projected Leaf Area) was higher than the provisional critical dose of $4 \mathrm{mmol} \mathrm{m}^{-2}$ PLA for forests. The cumulated dose showed two different growth rates in the spring and in the summer periods, while the exposure showed a more irregular behavior in both periods.
\end{abstract}

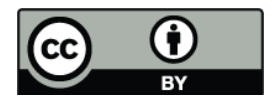

Correspondence to: G. Gerosa (giacomo.gerosa@unicatt.it)

\section{Introduction}

The toxicity of ozone for plants has been widely documented over the past twenty years (Benton et al., 2000; Skärby et al., 1998). Even when ozone does not bring to visible damage on the leaf lamina (Bermejo et al., 2003; Novak et al., 2008; Marzuoli et al., 2008), it remains a cause for physiological alterations and a general loss in Net Primary Productivity (NPP) (Felzer et al., 2004; King et al., 2005).

Mediterranean ecosystems, because of their climatic conditions and their proximity to anthropic sources of ozone precursors, are among the most exposed ecosystems to this pollutant (Paoletti et al., 2006). The EMEP model estimated for the Mediterranean areas an exposure between 40000 and $60000 \mathrm{ppb}$ h (on a six months basis, April-September) for the year 2000 (Simpson et al., 2007; Emberson et al., 2007), a value exceeding from 8 to 12 times the critical level of $5000 \mathrm{ppb}$ h set by UN-ECE for the protection of forests and seminatural vegetation. The year 2000 was chosen as the reference year since all the papers published by the authors of the model and its further developments and adjustments (EMEP-DO3SE model) have been referred to the same year/dataset.

Nevertheless field observations never reported a particularly strong plant injury (Bussotti and Gerosa, 2002; Bussotti et al., 2006, Paoletti et al., 2006), thus questioning the soundness of the exposure concept applied to ozone risk assessment. However, the lack of visible injuries in the Mediterranean vegetation could be due to extremely efficient physiological and biochemical defense mechanisms of these plants to oxidative stress as some experiments in controlled environments revealed (Nali et al., 2004; Elvira et al., 2004).

Among the physiological responses, stomatal regulation plays an important role because the reduction of the stomatal conductance due to the water limitation typical of the

Published by Copernicus Publications on behalf of the European Geosciences Union. 
Mediterranean summer implies a lowering of the ozone uptake by plant and hence of the effects of this pollutant.

Because of the crucial role of stomata in regulating the dose absorption process, the cumulative ozone flux $\left(\mathrm{AF}_{s t} \mathrm{Y}\right)$ has been chosen by UN-ECE as a more reliable ozone risk index then AOT40 (Musselmann et al., 2006; Karlsson et al., 2007, Matyssek et al., 2007). This index is based on the accumulation of stomatal fluxes over a threshold (Y) which accounts for the biochemical detoxification mechanisms. This threshold value has been provisionally set to $1.6 \mathrm{nmol} \mathrm{m}^{-2} \mathrm{~s}^{-1}$ (Karlsson et al., 2004) for forests and $6 \mathrm{nmol} \mathrm{m}^{-2} \mathrm{~s}^{-1}$ for crops (Pleijel et al., 2004), however the meaning and usefulness of $Y$ is still debated and discussed in the UN-ECE effects-based community. Despite the acknowledged better biological soundness of $\mathrm{AF}_{s t} \mathrm{Y}$ over AOT40 (Matyssek et al., 2007, Karlsson et al., 2007) AOT40 is still widely used since field measurements of $\mathrm{AF}_{s t} \mathrm{Y}$ are difficult. The calculation of AFstY from the observation in the field, in fact, requires the setting up of non-routinely monitoring systems, such as 3-D sonic anemometers and fast gas analysers for the Eddy Covariance micrometeorological technique (Keronen et al., 2003), branch chambers or similar and sap flow systems, which require the use of not completely standardized complex equipment. On the contrary the evaluation of AOT40 requires only ambient air ozone concentrations which are routinely monitored by the national or regional survey networks.

Moreover, the derivation of bulk stomatal flux from micrometeorological measurements requires the application of dry deposition inferential methods, data checking and gapfilling techniques which may not be completely automated. As a consequence, flux based risk assessments is mostly performed with the aid of models, such as the deposition module $\mathrm{DO}_{3}$ SE (Emberson et al., 2007; Ashmore et al., 2007) included in the EMEP model rather than a network of ozone flux monitoring stations.

Unfortunately, $\mathrm{DO}_{3} \mathrm{SE}$ has been validated mostly with observations of total $\mathrm{O}_{3}$ flux and stomatal conductance (gs) in ecosystem types which are representative of the Central and Northern Europe (e.g. Tuovinen et al., 2001). In Mediterranean conditions only one comparative study on wheat (Tuovinen et al., 2004) has been conducted in Italy and, to date, validation and comparison are still missing for an evergreen Mediterranean forest or the Mediterranean maquis. In fact it is important to test the model in conditions where high ozone concentrations can occur with high soil and atmospheric water deficits (Emberson et al., 2005).

Moreover a great amount of the ozone deposited to the ecosystems can be depleted prior to be absorbed by stomata. This non-stomatal deposition have been reported by many authors (e.g. van Pul and Jacobs, 1994; Fowler et al., 2001; Altimir et al., 2004, 2006; Gerosa et al. 2003, 2004, 2009a; Cieslik 2009a) and it was attributed to ozone destruction over plant and soil surfaces (van Pul and Jacobs, 1994), thermal decomposition mediated by solar radiation (Fowler et al., 2001; Rondón, 1993), gas phase reaction with biogenic volatile organic compounds (Kurpius and Goldstein, 2003) or with nitric oxide emitted by soils (Dorsey et a., 2004; Pilegaard et al., 1999), reaction with air humidity and water films (Altimir et al., 2004; 2006). However, the nature of this deposition is still not completely clear and further research is needed. Nevertheless the knowledge of the amount of ozone deposited by non-stomatal pathways is important for the ozone risk assessment since it affects the ozone fluxes to the ecosystems as well as the ozone concentrations at the leaf level thus leading to the ozone uptake by stomata.

This article is aimed to the analysis of the ozone flux dynamics and their interaction with $\mathrm{NO}_{\mathrm{x}}$ in a water limited environment during the dry season, and to offer a dataset of measurements suitable for model calibration and validation. It is also aimed at assessing the ozone risk for a Mediterranean maquis ecosystem, by the measurement of the dose actually absorbed by the vegetation through stomata and its comparison with AOT40.

\section{Materials and methods}

Measurements were performed from 5 June to 31 July 2007 in a coastal Mediterranean maquis at Castelporziano, Italy (N 41 $\left.{ }^{\circ} 40^{\prime} 49.3^{\prime \prime}, \mathrm{E} 12^{\circ} 23^{\prime} 30.6^{\prime \prime}\right)$.

Due to the poorness of the sandy soil the vegetation of this site do not develop completely. The ecosystem is kept in a dynamic equilibrium between two different succession stages of the maquis: low maquis and medium maquis (corresponding to low matorral and middle matorral sensu Tomaselli 1981). Ninety percent of the ground is covered by 6 main species: Quercus ilex, Arbutus unedo, Rosmarinus officinalis, Cistus spl, Phyllirea latifolia, Erica multiflora.

The average height of vegetation was around $120 \mathrm{~cm}$. About $90 \%$ of vegetation falls in a range plus or minus $30 \mathrm{~cm}$ from the average height, while the remaining $10 \%$ was characterised by the occurrence of few Quercus ilex and Arbutus unedo individuals which were on average $50 \mathrm{~cm}$ higher. More details on the measuring site can be found in Fares et al. (2009)

Two different techniques were used to measure turbulent fluxes of energy and matter: the eddy covariance technique and the gradient approach. A Dry Deposition Inferential Method approach (Wesely and Hicks, 2000; Gerosa et al., $2003,2004,2005)$ was then applied to calculate the ozone stomatal fluxes and the toxicological dose absorbed by the ecosystem.

\subsection{Instrumentation}

Sensible and latent heat fluxes as well as ozone fluxes were measured using the eddy covariance technique (Swinbank, 1951; Hicks and Matt, 1988). An ultrasonic anemometer (USA-1, Metek, Elmshorn, Germany), a $\mathrm{CO}_{2} / \mathrm{H}_{2} \mathrm{O}$ open path 
fast sensor (LI-7500, LI-COR, Lincoln, Neb., USA) and a fast ozone analyser (COFA, Ecometrics, Italy) were mounted on the top of a $3.8 \mathrm{~m}$ tall scaffold.

One net radiometer (NR lite, Kipp \& Zonen, Holland), one PAR meter (190SA, LI-COR, Lincoln, Neb., USA) and a temperature and relative humidity probe (50Y, Campbell Scientific, Shepshed, UK) were placed at the same height than the anemometer. An additional reference $\mathrm{O}_{3}$ analyzer (S-5014, SIR, Spain), sampling air at the top of the scaffold near the fast ozone sensor, was also used.

$\mathrm{NO}$ and $\mathrm{NO}_{2}$ fluxes were measured by a $\mathrm{NO}_{\mathrm{x}}$ analyzer ( $\mathrm{S}$ 2308 , SIR, Spain) using the gradient approach, measuring the nitrogen oxides concentrations alternatively at two different heights by means of an electro-valve switching system controlled by a computer with a LabView (National Instruments, Austin, Tx, USA) software. The two sampling points were chosen at $3.8 \mathrm{~m}$ and $1.3 \mathrm{~m}$.

The measuring site was equipped with additional instrumentation to better describe the temperature and humidity profile, the soil water status, the energy fluxes and the microclimate of the area: two additional temperature and relative humidity probes (50Y, Campbell Scientific, Shepshed, $\mathrm{UK}$ ) at $1 \mathrm{~m}$ and $0.1 \mathrm{~m}$; three soil heat flux plates, (HFP01SC, Hukseflux, Delft, Holland); three TDR reflectometers (C616, Campbell Scientific, Shepshed, UK); one rain gauge (52202, Young/Campbell Scientific, Cambridge, UK); one barometer (PTB101B,Vaisala, Finland); three leaf temperature probes (Pt100, DeltaT, UK) and two surrogate leaves (237, Campbell Scientific, UK) to measure leaf wetness.

The latter sensors are circuit boards of $6 \times 8 \mathrm{~cm}$ epoxyfiberglass green coloured resin with interlacing gold-plated fingers. Condensation on the sensors lowers the resistance between the fingers, which is measured by the datalogger. Sensors were not coated with latex paint and were mounted horizontal to the soil at $1 \mathrm{~m}$ height, with the grids facing up, just over two Holm oak bushes $3 \mathrm{~m}$ away from the measuring tower. Despite the Campbell 237 manual indicate a $150 \mathrm{~K} \Omega$ as a wetness/dryness threshold, in order to enhance the sensor sensitivity and promptness a very high dryness threshold of $6 \mathrm{M} \Omega$ was set, so all the conditions in which a resistance value was less than $6 \mathrm{M} \Omega$ were classified as wet canopy conditions.

Fast sensors were sampled at $20 \mathrm{~Hz}$ by a computer with a customised software written in Delphi 5.0 (Borland). Slow sensors were sampled every 15 seconds and data were collected by a datalogger (CR10x, Campbell Scientific, Shepshed, UK) equipped with a signal multiplexer device (AM16/32, Campbell Sci., UK), and data were averaged every $30 \mathrm{~min}$.

\subsection{Eddy-covariance}

Eddy covariance is a turbulence based technique which states that fluxes are equal to the covariance between the vertical component of the wind $(w)$ and the measured scalar quan- tity. Originally developed by Swinbank (1951), it has been accurately described and widely used for gas exchange measurements (e.g. Stull, 1988; Kaimal and Finnigan, 1994; Foken, 2008).

Under some conditions that have to be fulfilled (stationarity of the variables for which vertical fluxes are calculated, horizontal homogeneity, absence of chemical sources and sinks between the measuring height and the exchanging surface, and average vertical wind component equal to zero; Grünhage et al., 2000) vertical fluxes are constant with height and ozone, sensible and latent heat fluxes can be calculated as follows

$$
\begin{aligned}
& F_{\mathrm{O}_{3}}=\overline{w^{\prime} C^{\prime}} \quad(\mathrm{ppb} \mathrm{m} / \mathrm{s}) \\
& H=\rho c_{p} \overline{w^{\prime} T^{\prime}} \quad\left(\mathrm{W} \mathrm{m}^{-2}\right) \\
& \lambda E=\lambda \rho \overline{w^{\prime} q^{\prime}} \quad\left(\mathrm{W} \mathrm{m}^{-2}\right)
\end{aligned}
$$

where $C$ is the ozone concentration (ppb), $T$ the air temperature $\left({ }^{\circ} \mathrm{C}\right), q$ the specific humidity of the air $(\mathrm{Kg}$ vapor $/ \mathrm{Kg}$ air), $\rho$ the air density $\left(\mathrm{Kg} \mathrm{m}^{-3}\right), \lambda$ the constant of water vaporization $\left(\mathrm{J} \mathrm{Kg}^{-1} \mathrm{~K}^{-1}\right)$, and $c_{p}$ the specific heat of the air $\left(\mathrm{J} \mathrm{Kg}^{-1} \mathrm{~K}^{-1}\right)$. The primes (') indicate fluctuations of each variable around their mean and the overbars represent averages over a chosen time period, in our case a $30 \mathrm{~min}$ averaging period. This period is short enough to separate synoptic and diurnal variations from the turbulent data (van der Hoven, 1957), and long enough to include all turbulent fluctuations occurring in the atmospheric surface layer.

At the end of each $30 \mathrm{~min}$ averaging period, the fluctuations around the means were calculated after linear detrending of the data series and a covariance matrix was calculated, i.e. the covariances between every considered parameter and each other. Then the covariance matrix was rotated following the three rotations suggested by McMillen (1988) in order to eliminate the advective components resulting from small non-homogeneities of the exchanging surface and an eventual slight vertical tilt of the instrumentation.

In order to ensure a perfect synchronization of the data series and to account for different instrumental delays, the data series of the variables acquired by fast sensors were lagged with successive steps of $0.05 \mathrm{~s}$, with respect to the wind data series, until the calculated fluxes reached their maximum value. When a maximum flux value was not found within the 60th lag, the sample was recognized as not stationary and discarded.

\subsubsection{Data selection}

In addition to the previous method, the fulfillment of the stationarity requirement has been checked by using the selection criterion proposed by Dutaur et al. (1999). This criterion requires that fluctuations are calculated in two different ways: as the difference of the linear detrended series with the 30-min average, and as the difference with an instantaneous 
local running mean obtained by passing a mathematical $\mathrm{R}-\mathrm{C}$ recursive filter (analogous of an electric circuit of a resistor and a capacitor in series) over the original time series. If the normalized absolute difference between the covariances calculated with the fluctuations obtained with the two methods is below 1 , the sample was considered as stationary and reliable. On the contrary, the sample was discarded.

Other data selection criteria were that the data capturing efficiency of each sample had to be greater than $85 \%$, and that the canopy had to be completely dry. Only the data that passed these selections were used for successive analysis.

\subsubsection{Calculation of stomatal fluxes by a Dry Deposition Inferential Methodology}

The deposition of a gas depends on many variables such as wind velocity, friction velocity, incoming radiation, temperature, surface type, etc. In the Dry Deposition Inferential Method approach (DDIM) the deposition surface is treated as a "big leaf" located at a height $d+z_{0}$ over the soil, where $d$ is the displacement height accounting for the canopy height $h$ (set to $2 / 3$ of the $h$ ) and $z_{0}$ is the roughness length which accounts for the canopy roughness (set to $12 / 100 \mathrm{of} h$ ). Three main phases are considered in the deposition process: first of all the gas must overcome the aerodynamic resistance $\left(R_{a}\right)$ existing in the turbulent layers of the atmosphere above the studied surface; then the gas must move across the quasilaminar sub-layer which is characterized by a molecular diffusion against the so-called sub-laminar resistance $\left(R_{b}\right)$; finally, in order to reach the surface, the gas must overcome the resistance of the surface itself $\left(R_{c}\right)$. The deposition flux of a gas is hence considered as the analogous of a current flowing through a electric circuit composed by these three resistances in series. Their equivalent resistance is called total resistance $\left(R_{\text {tot }}\right)$ and it is equal to the concentration of the gas at the measuring point divided by the deposition (i.e. $<0$ ) flux $F_{\mathrm{O}_{3}}$ :

$R_{\mathrm{tot}}=R_{a}+R_{b}+R_{c}=C_{z m} /\left(-F_{O_{3}}\right) \quad \forall F_{\mathrm{O}_{3}}<0$

The aerodynamic resistance $R_{a}$ was calculated using the well known similarity relation introduced by Monin and Obukhov (1954), while the sub-laminar resistance $R_{b}$ for ozone was calculated following the general purpose parameterization proposed by Hicks et al. (1987). The surface resistance $R_{C}$ is hence obtained as a residual since $R_{\text {tot }}$ is known, because it is derived from directly measured entities $\left(C_{z m}\right.$ and $\mathrm{F}_{\mathrm{O}_{3}}$ ).

In order to estimate the fraction of gas penetrating through the stomata of plants, the surface resistance $R_{c}$ (also called the canopy resistance in ecology) is broken down into a stomatal resistance and a non-stomatal one mounted in parallel.

The stomatal resistance to ozone, $R_{S T}$, has been calculated from the stomatal resistance to water evaporation $R_{w}$ by inverting the Penmann-Monteith equation (Monteith, 1981) i.e. by solving this equation for $R_{w}$ since all the other entities are directly known from measurements- and by considering the relative diffusivity ratio of ozone in air to that of water vapour (Massman, 1998), set equal to 0.61 following the average $T$ and $P$ conditions at this site.

The non-stomatal resistance was calculated as a residual from $R_{c}$ and $R_{S T}$, following the rules of the parallel resistances. The stomatal ozone flux was hence obtained as

$F_{S T}=\frac{R_{c}}{\left(R_{a}+R_{b}+R_{c}\right) R_{S T}} C_{z m}$

Further details can be found in Gerosa et al. (2005).

Samples where the inferred values of $\mathrm{Ra}$ and $\mathrm{Rb}$ exceeded $10000 \mathrm{~s} \mathrm{~m}^{-1}$ were rejected, because unrealistic. The same was done for samples where $R_{c}$ resulted lower than 0 because the sum of $R_{a}$ and $R_{b}$ exceeded the measured total resistance to ozone ( $R_{c}$ was obtained as a residual) or when $R_{S T}$ was not computable because the Penman-Monteith equation could not be inverted, e.g. when $\lambda E$ was not positive. A threshold value of $10000 \mathrm{~s} / \mathrm{m}$ was applied to the stomatal resistance when its value increased above this value assumed to be representative of the cuticular resistance.

Finally, in order to preserve a numerical coherence, if the estimation of one resistance failed, then all the sample were discharged, even though the values of the other resistances seemed reasonable.

\subsubsection{Ozone dose and exposure}

In this work both exposure and dose approaches were compared. The exposure was calculated as AOT40 for daylight hours only:

$$
\text { AOT40 }=\sum_{\forall \text { GlobRad } \geq 50 \mathrm{~W} / \mathrm{m}^{2}} \max \left(0 ; C_{d+z_{0}}-40\right) \Delta t
$$

where $\Delta t$ is the averaging period for the ozone concentration measurements $(1 \mathrm{~h})$. The concentration at $d+z_{0}$, recommended by the ICP modelling and mapping manual (2004), was calculated with the Dry Deposition Inferential Method (Gerosa et al., 2005):

$C_{d+z_{0}}=C_{z m}\left(1-R_{a} / R_{\text {tot }}\right)$

The ozone dose received by the ecosystem in the whole measuring period (May-July) was calculated as $\mathrm{AF}_{s t} 0$ by summing up all the 30-min ozone stomatal fluxes $F_{s t}$ of the period

$A F_{s t} 0=\sum \max \left(0 ; F_{s t}\right) \Delta t$

where $\Delta t$ is the averaging period chosen for eddy covariance measurements.

The dose was also calculated as $\mathrm{AF}_{s t}$ 1.6:

$\mathrm{AF}_{s t} 1.6=\sum \max \left(0 ; F_{s t}-1.6\right) \Delta t$

where $F_{s t}$ is the stomatal ozone flux obtained by the DDIM, $1.6 \mathrm{nmol} \mathrm{m} \mathrm{m}^{-2} \mathrm{~s}^{-1}$ is the UN-ECE detoxification threshold and $\Delta t$ is the averaging period of the flux measurements. 


\subsubsection{Data gap-filling}

The results presented in this paper rely on the measured data that fulfilled all the selection criteria. One unique exception has been made for the assessment of the exposure and the dose.

In fact, since both AOT40 and the ozone dose are cumulative metrics, a gap in ozone concentrations and ozone fluxes will result in an unavoidable underestimation of their values.

To reduce such underestimation a gap-filling was performed. Gaps of no more than 3 consecutive 30-min averages were linearly interpolated, while large gaps were gap-filled with time series reconstructed by multiple linear regression based on available predictors as local meteorological parameters and ozone concentrations from a nearby measuring station.

Gaps in stomatal fluxes could result also as a consequence from data rejection at the output of the DDIM process. In these cases stomatal fluxes were estimated by taking the average stomatal fraction (the ratio between $F_{s t}$ and $F_{\text {tot }}$, based solely on measured data) at the corresponding half an hour, and by multiplying it by the available total ozone flux .

\subsection{Gradient approach}

The aerodynamic gradient has been widely used to estimate surface fluxes (Grunhage et al., 2000; Foken, 2008) since, unlike eddy covariance, it does not require fast analyzers. Here the turbulent diffusion coefficient for heat $K_{H}$, that takes into account also the vertical stability of the atmosphere, was easily available from eddy covariance data and applied to both nitric oxide and nitrogen dioxide fluxes, following the similarity of the transport of each scalar entity found by Monin and Obhukhov (1954) (Stull, 1988; Monteith and Unsworth, 1990; Pal Arya, 1988). Nitrogen oxides fluxes were hence calculated for each half-hours as follows:

$F_{\mathrm{NO}_{\mathrm{x}}}=-K_{H} \cdot \Delta\left[\mathrm{NO}_{\mathrm{x}}\right] / \Delta z$

where $\mathrm{NO}_{\mathrm{x}}$ indicates the $\mathrm{NO}$ concentrations when calculating the $\mathrm{NO}$ fluxes $\mathrm{F}_{\mathrm{NO}}$ and the $\mathrm{NO}_{2}$ concentrations when calculating the $\mathrm{NO}_{2}$ fluxes $F_{\mathrm{NO}_{2}}, \Delta\left[\mathrm{NO}_{\mathrm{x}}\right]$ is the mean difference of $\mathrm{NO}$ and $\mathrm{NO}_{2}$ concentrations between the two measuring heights $z_{2}$ and $z_{1}$, and $\Delta z$ is $z_{2}-z_{1}$, equal to $2.5 \mathrm{~m}$ in our case.

\section{Results}

A total of 4176 semi-hourly samples were gathered during the whole measuring period. The samples referred to completely dry canopy conditions were 1894 (45.3\%), because nearly all the samples between 8 p.m. and 8:30 a.m. were excluded due to the presence of dew on the leaves. This subdataset was further reduced by $16 \%$ because instrumental drawbacks (e.g. shut down, instrument breakings and substitutions), and by another $33.2 \%$ following the exclusion of the data which did not fulfill the stationarity conditions. Hence the output of the DDIM analysis is based on the $50.8 \%$ of the data gathered from 8:30 a.m. to 8 p.m., except when explicitly indicated.

In order to highlight different physiological traits, most of the results are split in two different periods: the first one from 5 May to 12 June (late spring) and the second one from 13 June to 31 July (summer).

\subsection{Ozone concentrations and fluxes}

The average ozone concentration at the measuring height was $32.6 \mathrm{ppb}$ in the first period and $38.6 \mathrm{ppb}$ in the second one. The overall average was $35.9 \mathrm{ppb}$ and the maximum peak concentration was $107 \mathrm{ppb}$. Ozone concentrations were strongly influenced by the local meteorology: higher concentrations were observed when the wind was blowing from the sea and lower concentrations downwind to the city of Rome. Ozone concentrations usually began to increase early in the morning, around $8 \mathrm{a} . \mathrm{m}$. reaching their daily maximum in the first afternoon, and decreased to the lower nighttime values afterwards (Fig. 1). With the only exception of some days with high nighttime values, ozone concentrations showed a typical bell-shaped behavior.

On the contrary, the total ozone fluxes appear more irregular because of their intrinsic link to the atmospheric turbulence. Substantial differences in the daily maximum absolute values (Fig. 1), which are usually reached in the first hours of the afternoon, are evident. A significant reduction of the average total ozone fluxes occurred in the second period: in the first period the absolute values of total fluxes were between 15 and $20 \mathrm{nmol} \mathrm{m}^{-2} \mathrm{~s}^{-1}$ for a large part of the day ( 8 a.m. to 7 p.m.), while in the second period they were around 10 to $12 \mathrm{nmol} \mathrm{m}^{-2} \mathrm{~s}^{-1}$ (Fig. 2). Also nighttime absolute values of the total fluxes were slightly greater in the first period (about $7 \mathrm{nmol} \mathrm{m}^{-2} \mathrm{~s}^{-1}$ ) than the second one (about $\left.5 \mathrm{nmol} \mathrm{m}^{-2} \mathrm{~s}^{-1}\right)$.

The stomatal component of the ozone flux decreased as a consequence of stomatal response to a decreased water availability in the soil and an increased VPD in air (Mereu et al., 2009a).

Figure 3 highlights the reduction in evapotranspiration that follows the decrease in soil water content (SWC). In the late spring the ecosystem could rely on a relatively high SWC, especially from the lower soil strata. In summer, the ecosystem experienced dryer conditions, since water depletion involved the deeper soil layers and the water table itself became shallower. Consequently, an increasing fraction of the available energy was thermically dissipated, while the fraction used for evapotranspiration decreased by more than $60 \%$, from $105 \mathrm{~W} \mathrm{~m}^{-2}$ to $45 \mathrm{~W} \mathrm{~m}^{-2}$ in the central hours of the second period (Fig. 4).

Also stomatal fluxes decreased their absolute diurnal mean value by $44 \%$ between the first and the second period. Moreover their diurnal behavior changed too, as described in 
a)

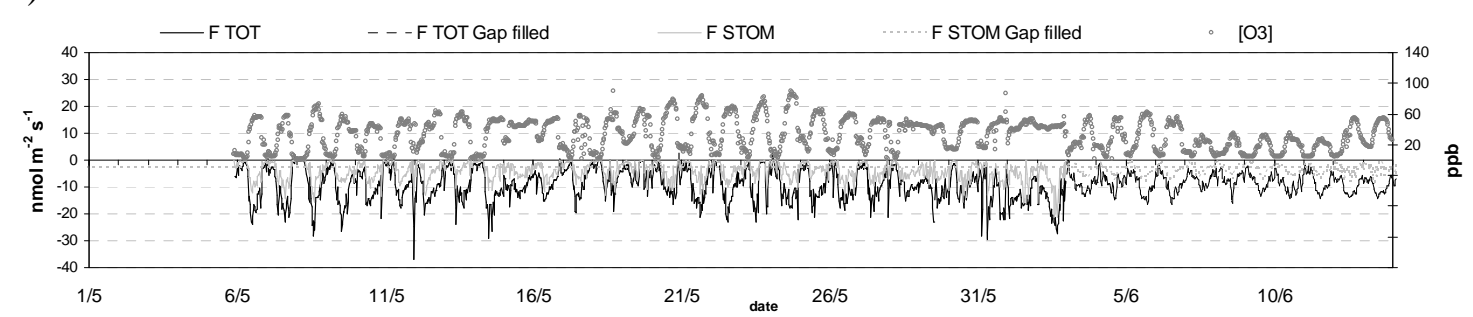

b)

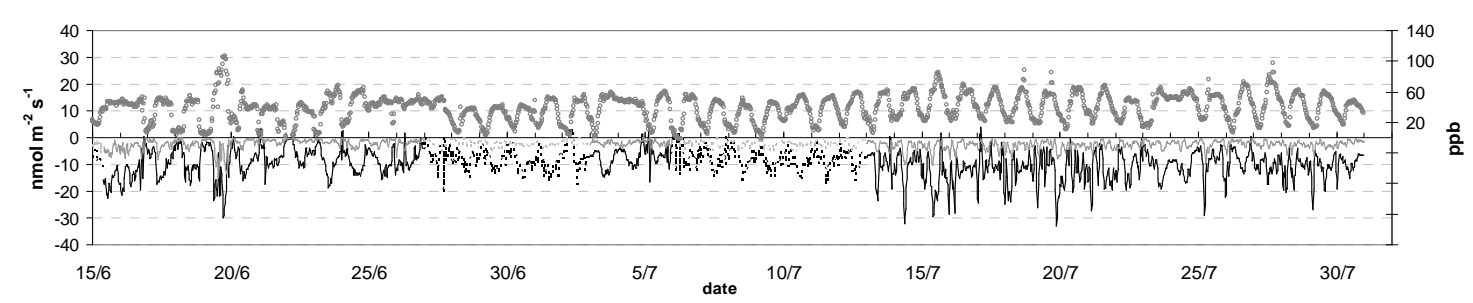

Fig. 1. Ozone concentration and ozone fluxes in the spring period (a) and the summer period (b). The dark line is the total ozone flux to the ecosystem and the gray line is the stomatal flux (left axis), i.e. the amount of ozone taken up by vegetation through stomata. Circles represent ozone concentrations (right axis) and dashed dark and gray lines are gap-filled values of total ozone flux and stomatal ozone flux, respectively.

a)

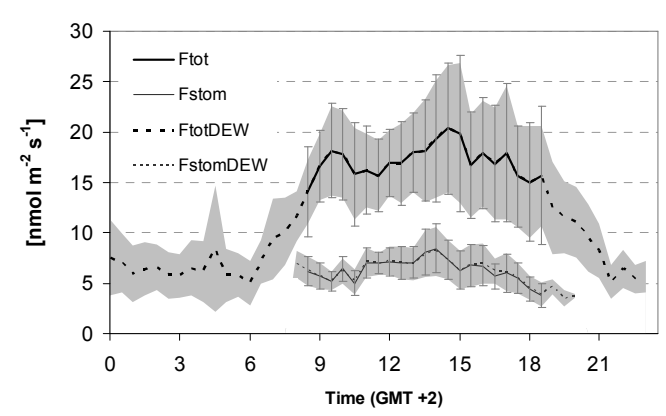

b)

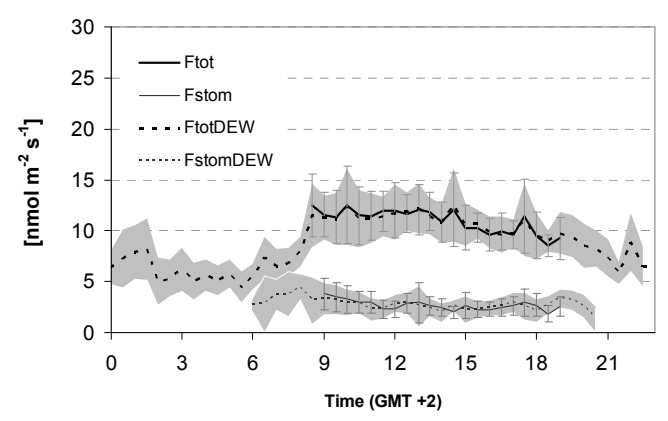

Fig. 2. Mean daily course of the absolute values of total and stomatal ozone fluxes. (a) Spring period (6 May-12 June). (b) Summer period (13 June-31 July). $F_{\text {tot }}$ and $F_{\text {stom }}$ are the total and the stomatal ozone fluxes when the canopy were completely dry, i.e. excluding the periods

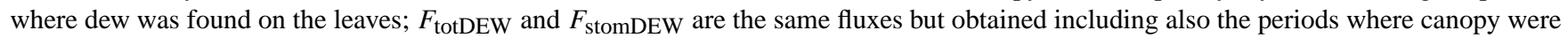
wet. Vertical bars are the standard deviations referred to $F_{\text {tot }}$ and $F_{\text {stom }}$ while the shaded areas represent the standard deviations of $F_{\text {totDEW }}$ and $F_{\text {stomDEW. }}$

Fig. 2. In the first period ozone stomatal uptake showed a slight increase from the morning hours to the first hours of the afternoon (from 5 to $8 \mathrm{nmol} \mathrm{m}^{-2} \mathrm{~s}^{-1}$ ), and afterwards it decreased back to $5 \mathrm{nmol} \mathrm{m}^{-2} \mathrm{~s}^{-1}$ in the evening. In the second period stomatal fluxes were about $4 \mathrm{nmol} \mathrm{m}^{-2} \mathrm{~s}^{-1}$ around 9 a.m. and slightly decreased to a constant value reached at midday (around $2.5 \mathrm{nmol} \mathrm{m}^{-2} \mathrm{~s}^{-1}$ ), then remained unvaried until sunset.

These stomatal fluxes were compared with the ozone stomatal uptake derived from sap flow measurements performed simultaneously on three species in the same site (Mereu et al., 2009). Sap-flow measurements allow the cal- culation of plant specific stomatal conductance that can be used for a qualitative comparison with the ecosystem level EC measurements. In Fig. 5 the sap flow-derived uptake is obtained by summing up each species uptake, upscaled by the species specific LAI and percentage cover as reported by (Fares et al., 2009). The ozone flux attributed to these species shows a similar trend to that estimated from EC. In the first period, fluxes rapidly increased in the morning hours from values of less than $1 \mathrm{nmol} \mathrm{m}^{-2} \mathrm{~s}^{-1}$ to values of about $7 \mathrm{nmol} \mathrm{m}^{-2} \mathrm{~s}^{-1}$ around 11:30 a.m. and gradually decrease afterwards. In the second period, the morning increment was significantly lower and fluxes reached a value of 
$2.5 \mathrm{nmol} \mathrm{m}^{-2} \mathrm{~s}^{-1}$ already at 10:30 and remained steady for most of the day.

As a consequence of the different water availability, the stomatal fraction of the ozone flux absorbed by vegetation varied from a range of 40 to $50 \%$ of the total flux in the first period, to a range of $20-30 \%$ in the second period. In the latter case, it is interesting to note that the stomatal fraction was higher in the morning ( $45 \%$ around 9 a.m.), it rapidly decreased to a lower percentage for most of the day (Fig. 6) and slightly recovered to a $30 \%$ in the late afternoon.

\subsection{Ozone exposure and dose}

During the whole experimental period the ecosystem experienced an ozone exposure, expressed in terms of AOT40 for daylight hours of $20650 \mathrm{ppbh}$ (Fig. 7). Such a value is computed using ozone concentrations at $z_{m}=3.8 \mathrm{~m}$ a.s.l., but if it is computed with the concentrations at momentum sink height (more or less the top canopy height), i.e. at $d+z_{0}$, total exposure lowers to $8600 \mathrm{ppb}$.

In the same period the stomatal dose, computed as a cumulative stomatal flux without any cutting threshold $\left(\mathrm{AF}_{s t} 0\right)$, was $22.8 \mathrm{mmol} \mathrm{m}^{-2}$ PLA.

The exposure at $z_{m}$ during the measuring period shows an irregular growth which reflects the alternation of photochemical episodes with meteorological perturbations. The exposure at $d+z_{0}$, after the initial increment between 20 May and 25 May, grew more regularly due to the lower ozone concentrations at leaf level.

Dose development $\left(\mathrm{AF}_{s t} 0\right)$, instead, was less variable, but a more careful analysis reveals two distinct periods with two different ozone assimilation rates, periods corresponding to late spring and summer (Fig. 7). In both periods the dose grew almost linearly, at a rate of $0.17 \mathrm{mmol} \mathrm{m}^{-2} \mathrm{day}^{-1}$ in the first period and of $0.11 \mathrm{mmol} \mathrm{m}^{-2} \mathrm{day}^{-1}$ in the second. The two different rates clearly reflect the lower stomatal response in the second period. Also $\mathrm{AF}_{s t} 1.6$ showed a similar trait, but with a lower growth rate during summer. The $\mathrm{AF}_{s t} 1.6$ dose at the end of the measured period was $12.6 \mathrm{mmol} \mathrm{m}^{-2}$ PLA, about the half of the $\mathrm{AF}_{s t} 0(55.3 \%)$.

\subsection{Nitrogen oxides concentrations and fluxes}

Mean nitric oxide (NO) concentrations remained fairly constant in the central hours of the day around a mean value of 3-4 ppb (Fig. 8a). Concentrations slowly increased during the night reaching a peak value of $20 \mathrm{ppb}$ around 5 a.m., after which they decreased back to the typical diurnal values.

Nitrogen dioxide $\left(\mathrm{NO}_{2}\right)$ concentrations remained around 1-2 ppb during the diurnal hours and rose to $6 \mathrm{ppb}$ after sunset. Similarly to $\mathrm{NO}$, also $\mathrm{NO}_{2}$ concentrations showed a morning peak of $10 \mathrm{ppb}$ which occurred between 8 and 9 a.m.

Vertical fluxes of nitrogen oxides were considerably weaker than the already described ozone fluxes and were in general more variable. Nevertheless, the mean day trend

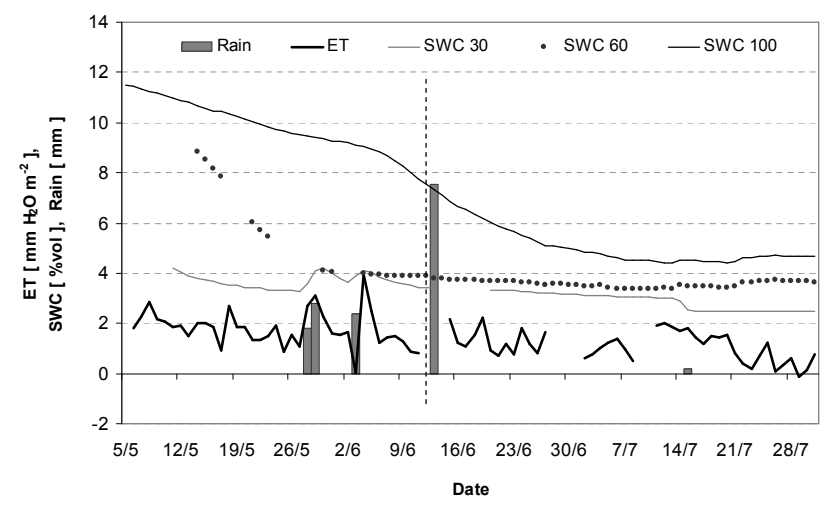

Fig. 3. Daily averages of evapotranspiration, rain and soil water content $(\mathrm{v} / \mathrm{v})$ during the whole measuring period. Soil water was measured at three different levels: $30 \mathrm{~cm}, 60 \mathrm{~cm}, 100 \mathrm{~cm}$. Vertical dotted line is the separation between the two periods.

(Fig. 8b) reveals some regularities. During the measuring period NO showed a median positive flux (exiting the ecosystem) during the day (between 8 and 18 a.m.) and an almost null flux in the remaining night hours. The peak value of the median flux was about $0.2 \mathrm{ppb} \mathrm{m} \mathrm{s}^{-1}( \pm 0.28 \mathrm{std}$. dev.)

On the contrary, the $\mathrm{NO}_{2}$ flux shows an almost constant median deposition rate around $0.06 \mathrm{ppb} \mathrm{m} \mathrm{s}^{-1}$ at night, with a weak peak of about $0.1 \mathrm{ppb} \mathrm{m} \mathrm{s}^{-1}( \pm 0.19)$ at 8 a.m. followed by an intense diurnal emission peak of $0.6 \mathrm{ppb} \mathrm{m} \mathrm{s}^{-1}$ $( \pm 0.39$ std. dev. $)$ around 1 p.m.

The net NO efflux could be the result of soil emissions below the vegetation, while the efflux of $\mathrm{NO}_{2}$ may be interpreted as a photochemical effect. As refereed by Gao et al. (1993) and Monson and Holland (2001), NO concentration show a steep decrease with height above the soil under a canopy, reaching a minimum near the middle of the canopy, while the $\mathrm{O}_{3}$ induced oxidation of $\mathrm{NO}$ to $\mathrm{O}_{3}$ within the canopy causes $\mathrm{NO}_{2}$ concentrations to be higher within the canopy than above resulting in a net efflux of $\mathrm{NO}_{2}$. The origin of such imbalance is not completely clear and could be attributed to advection, deposition and transformation by nighttime chemistry of nitrogen species transported from Rome by the city plume.

\section{Discussion}

The order of magnitude of the ozone dose received by the maquis ecosystem is comparable to the dose received by the Holm Oak forest positioned just $0.8 \mathrm{~km}$ inland (Gerosa et al., 2009a) and it is also similar to the amount absorbed by barley and wheat crops (Gerosa et al., 2003, 2004, 2005). Apparently, the dose does not vary greatly despite the evident structural differences of these ecosystems and the different leaf and canopy stomatal conductance. In all these cases, only a small portion of the ozone received by the ecosystem 
a)

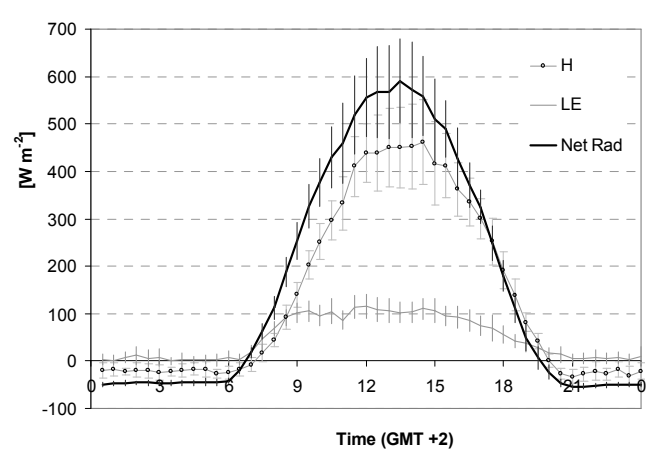

b)

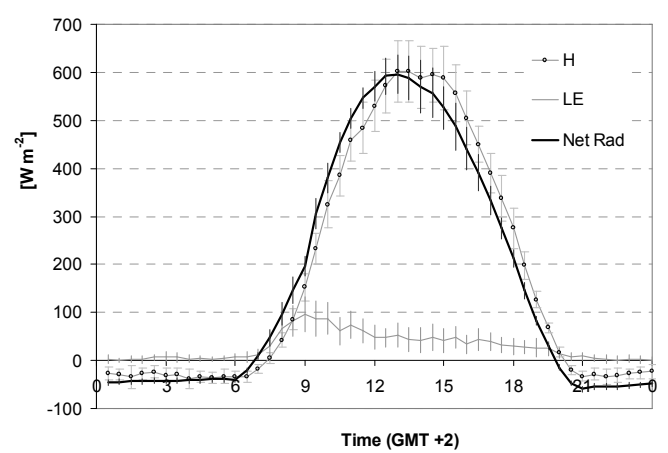

Fig. 4. Energy fluxes: available energy (net-radiation), sensible heat and latent heat. Mean daily course in (a) the spring period and (b) the summer period. Vertical bars are the standard deviations.

a)

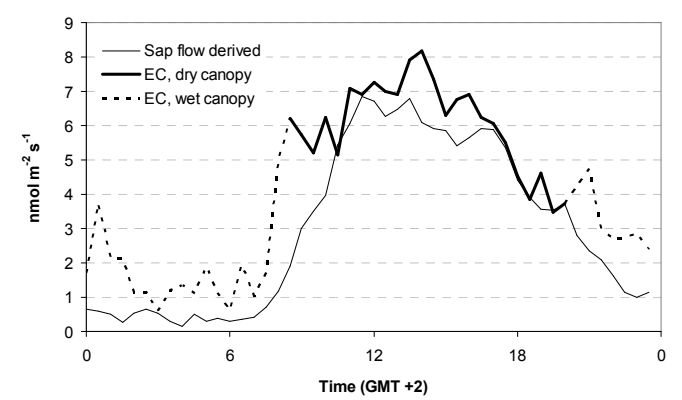

b)

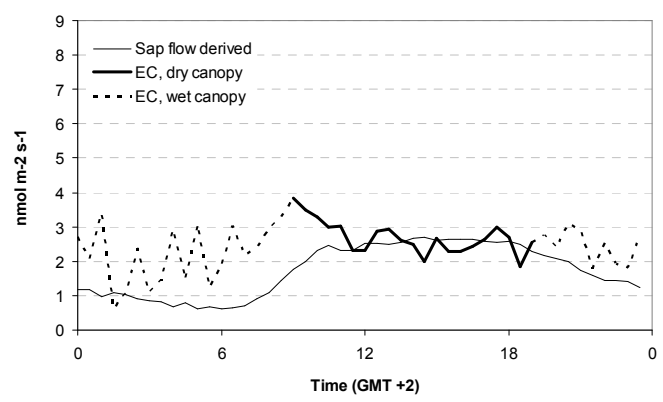

Fig. 5. Comparison of the ozone uptake (stomatal fluxes) obtained from the sap flow measurements and the eddy covariance (EC) measurements in the late spring (a) and summer (b) periods. Graphs show averaged values of fluxes in each half an hour of the two distinct periods.

is effectively absorbed by the stomata. The greatest part of ozone, instead, is depleted in chemical-physical processes that altogether are termed non-stomatal deposition.

\subsection{Stomatal uptake}

It is important to notice that night time hours are frequently characterized by thermal inversions, which determine the accumulation of dew over the canopy and soil (Cieslik et al., 2009b; Mereu et al., 2009). The formation of dew during the night, as well as the drying of the leaf lamina and the evaporation early in the morning, are confirmed by the leaf wetness sensors (Fig. 9). The evaporation of water from the surfaces might lead to a misinterpretation of the data and to an overestimation of the stomatal conductance. In Fig. 10 canopy stomatal conductance data are shown for both dry and wet canopy. Even if light intensity is sufficient to cue stomatal aperture already from the first hours of the morning (PPFD at 7 a.m. was around $300 \mu \mathrm{E} \mathrm{m}^{-2} \mathrm{~s}^{-1}$ ) the early morning peak of stomatal conductance appears unrealistic. In fact, the sap flux measurements performed on three species, (Mereu et al., 2009a) support this conclusion. With the only exception of the driest period (late July), sap flux showed a bell shaped trend and a peak in sap flux never occurred in the morning (Fig. 11). However, since the measured species only represent $38 \%$ of the total cover (Fares et al., 2009) it could be argued that the other species may be responsible for the morning transpiration peak. But even this eventuality should be excluded by the fact that also two of the unmeasured species (P. latifolia, C. incanus) are known to behave in a similar way for the transpiration rate (Bombelli and Gratani, 2003). The only exception could be Rosmarinus officinalis (17\% of the cover), but the SWC ( $\left.\Psi_{s}<-1 \mathrm{MPa}\right)$ was low enough to ensure a reduction of its stomatal conductance of more than $80 \%$ (Clary et al., 2004). It is hence most likely that the observed morning peak is an artifact attributable simply to dew evaporation.

It is for this reason that the presented results were filtered in order to exclude fluxes measured when the canopy was wet and in the following hour. This underlines the importance of 
a)

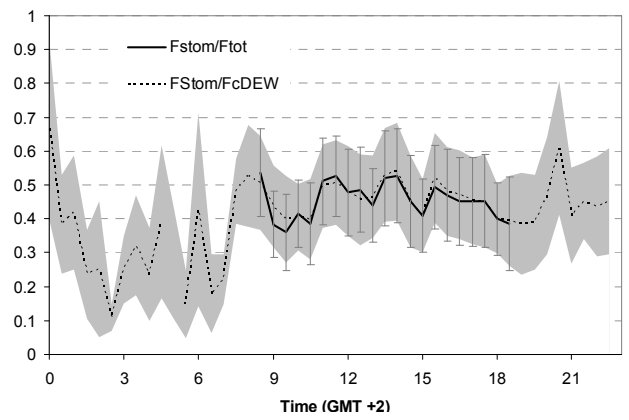

b)

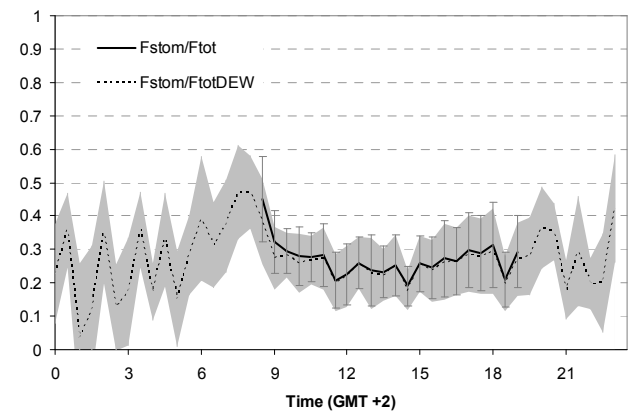

Fig. 6. Average stomatal fraction in the two periods (a) and (b). $F_{\text {stom }} / F_{\text {tot }}$ is the ratio of the stomatal flux to the absolute value of total deposition flux when the canopy were completely dry, i.e. excluding the periods where dew was found on the leaves; $F_{\text {stom }} / F_{\text {totDEW }}$ is the same ratio but obtained including also the periods where canopy were wet. Vertical bars are the standard deviations referred to $F_{\text {stom }} / F_{\text {tot }}$ while the shaded area represents the standard deviations of $F_{\text {stom }} / F_{\text {totDEW. }}$

verifying dry canopy conditions in EC based flux measurements, even in xeric environments, and the potential advantage of coupling EC measurements with sap flow gauges.

\subsection{Non-stomatal deposition}

The nature of the non-stomatal deposition $\left(F_{\text {nstom }}\right)$, more than $50 \%$ percent in this study, is still not understood and different hypotheses have been made to explain it. Van Pul and Jacobs (1994), after observing that the $F_{\text {nstom }}$ increased with the efficiency of ozone transport inside the canopy, suggested the cause to be the destruction of ozone over the plant and soil surfaces, since they observed that the ozone transport efficiency is proportional to $u^{*}$ and inversely related to the Leaf Area Index (LAI) and to the vegetation height. Instead, in a laboratory experiment Rondón (1993) showed that cuticular uptake by leaf waxes increased from a negligible rate at low levels of light intensity, to rates comparable with stomatal uptake at light levels equivalent to strong sunlight conditions, thus suggesting an important role of solar radiation. Fowler et al. (2001) suggested that the relationship between $F_{\text {nstom }}$ and radiation reported by Rondón (1993) and by Coe et al. (1995) could be explained as thermal decomposition of the ozone molecules intercepting the surfaces heated by radiation; they also estimated the energy of activation of this reaction to be $36 \mathrm{KJ} \mathrm{mol}^{-1}$. Kurpius and Goldstein (2003), instead, observed that the exponential form of the relationship between $F_{\text {nstom }}$ and temperature was similar to the relationship between temperature and the emission rate of Volatile Organic Compounds (VOC). Based on this similarity, they advanced the hypothesis that a great fraction of the daytime ozone deposition could be a consequence of gas-phase reactions with biogenic hydrocarbons and estimated that 45 to $55 \%$ of the total ozone flux could depend on such reactions. Loreto and Fares (2007) have shown the influence of monoterpenes on the removal of ozone both in the bound-

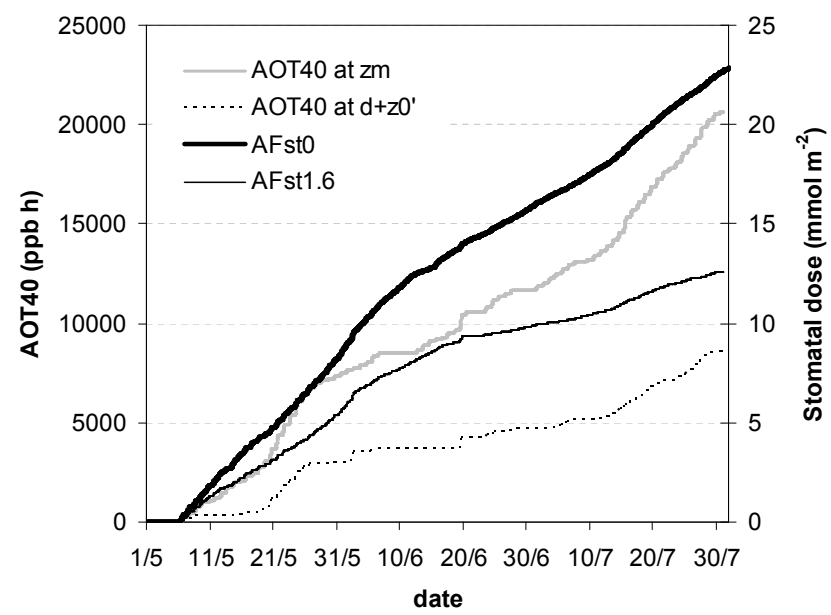

Fig. 7. Evolution of Ozone exposure and stomatal dose during the measuring period. The exposure is expressed as AOT40 calculated at measurement height and at momentum sink height $\left(d+z_{0}\right)$. The dose is expressed as cumulated stomatal flux $\mathrm{AF}_{s t} 0$, without any flux threshold, and as $\mathrm{AF}_{s t} 1.6$ after the application of the instantaneous flux threshold of $1.6 \mathrm{nmol} \mathrm{m}^{-2} \mathrm{~s}^{-1}$.

ary layer and inside the mesophyll, since the emission of monoterpenes was relevant at our site (Fares et al., 2009), monoterpenes reactions with ozone can play an important role in the non-stomatal deposition. However Mikkelsen et al. (2000) estimated from concurrently measured $\alpha$ - and $\beta$ pinene fluxes a maximum destruction potential of monoterpene emissions corresponding only to $10 \%$ of the total ozone flux.

A role in non-stomatal ozone depletion has been also attributed to gas-phase tritration reactions with biogenic emissions of NO. The measurements of Dorsey et al. (2004) and of Pilegaard et al. (1999), and the precedent models of 
a)

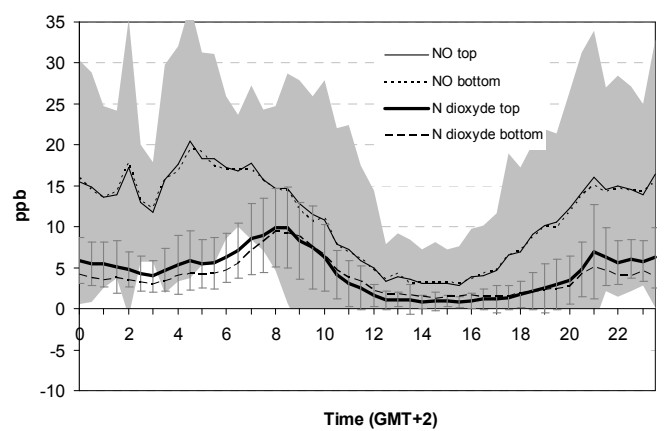

b)

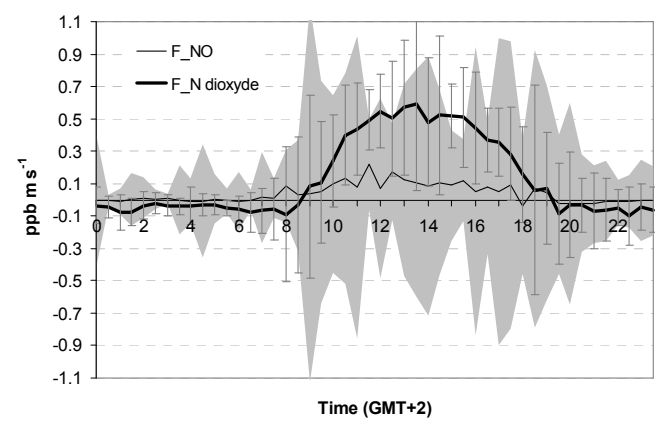

Fig. 8. (a) Mean daily course of $\mathrm{NO}$ and $\mathrm{NO}_{2}$ concentrations. Vertical bars are the standard deviations of the $\mathrm{NO}_{2}$ concentration at the top level while the shaded area represents the standard deviations of NO at the top level. (b) Median daily course of vertical fluxes of NO and $\mathrm{NO}_{2}$. Positive values are efflux and negative values are depositions. Vertical bars are the standard deviations of the $\mathrm{NO}_{2}$ fluxes, and the shaded area represents the standard deviations of the NO fluxes.

a)

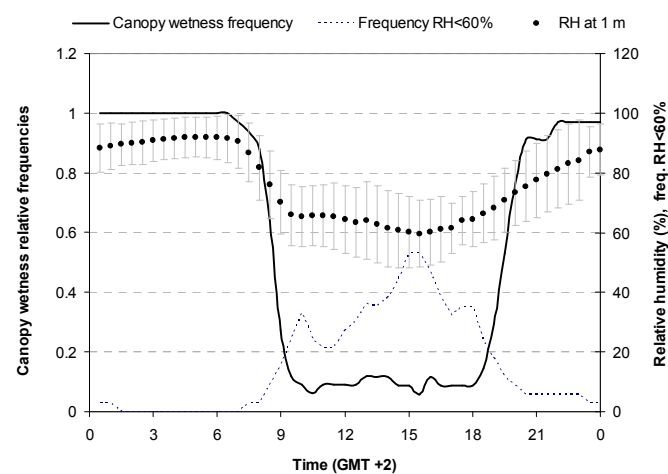

b)

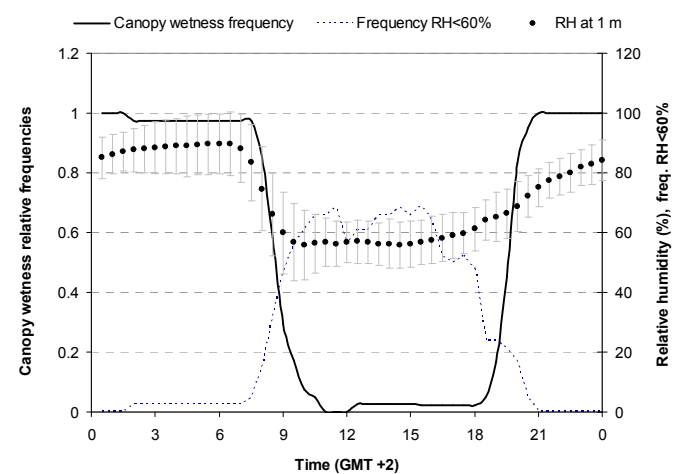

Fig. 9. Canopy wetness as measured by surrogate leaves. Frequency of canopy wetness (ratio of the number of half an hours with wet canopy to the total number of half an hours) in the different hours of (a) first and b) second period. Average course of relative humidity at canopy height $(1 \mathrm{~m})$ is showed too. Vertical bars are the standard deviations of RH. The dashed line indicates the relative frequency of relative humidity below $60 \%$ for each half an hour during the measuring period.

Duyzer et al. (1995) and Walton et al. (1997), highlighted that NO emissions from forest soils not only affect the magnitude and the direction of the $\mathrm{NO}_{2}$ fluxes, but also the intensity of ozone fluxes. Nevertheless, the influence on the latter is usually weak, but not negligible, and can become relevant in case of a high soil NO efflux (Pilegaard et al., 1999), when a substantial $(\sim 30 \%)$ amount of the total ozone flux could be accounted for by chemical reactions, especially at night (Pilegaard, 2001; Walton et al., 1997). Finally, Altimir et al. (2004) found an influence of the atmospheric humidity on non-stomatal deposition at night., with an hyperbolic increase of surface conductance to ozone with saturating $\mathrm{RH}$ $\%$.

In this study, the analysis of the data presented in Figs. 12 and 13 allows to support only the hypothesis of a direct influence of atmospheric humidity on non-stomatal deposition. A gas-phase reaction with $\mathrm{NO}$ of biogenic and antropic origin could be observed but only at high efflux rates as reported by Pilegaard et al. (1999).

The occurrence of this reaction is revealed by the hyperbolic dependence $\left(R^{2}=0.95\right)$ of Fnstom on the $\mathrm{NO}_{2}$ fluxes observed over the canopy (Fig. 12f).

The dependence on RH, instead, is revealed by the median values of non-stomatal conductance, that, increased linearly together with the absolute humidity of air $\left(R^{2}=0.63\right)$ and the relative humidity $\left(R^{2}=0.55\right)$ when the canopy was completely dry (Figs. 12d and 13a). When the canopy was wet (mostly at night in our site) the relationship became hyperbolic $\left(R^{2}=0.60\right)$ (Fig. 13b) as already found by Altimir et al. (2004). In this last case, ozone is not only removed by reactions with atmospheric water, but also dissolved in the water film deposited over the colder surfaces, i.e. leaves, 
a)

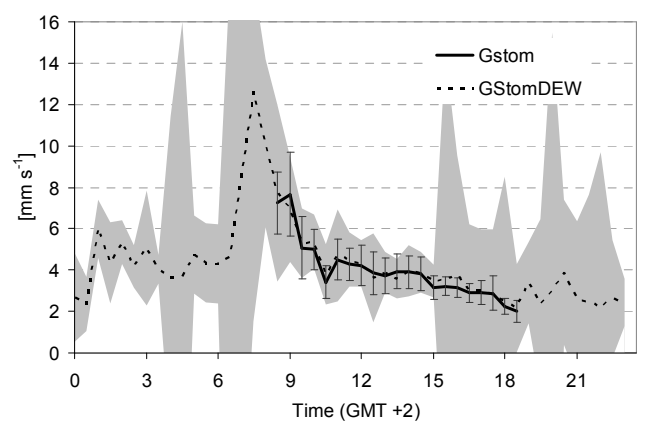

b)

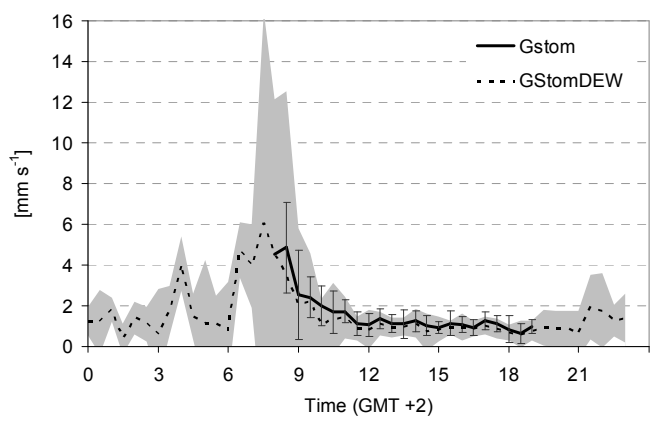

Fig. 10. Stomatal conductance of the ecosystem canopy. Median daily course in (a) the spring period and (b) the summer period. $G_{\text {stom }}$ is the stomatal conductance to ozone when the canopy were completely dry, i.e. excluding the periods where dew was found on the leaves; $G_{\text {stomDEW }}$ is the same conductance but obtained including also the periods where canopy were wet. Vertical bars are the standard deviations of $G_{\text {stom }}$ while the shaded area represents the standard deviations of $G_{\text {stomDEW }}$.
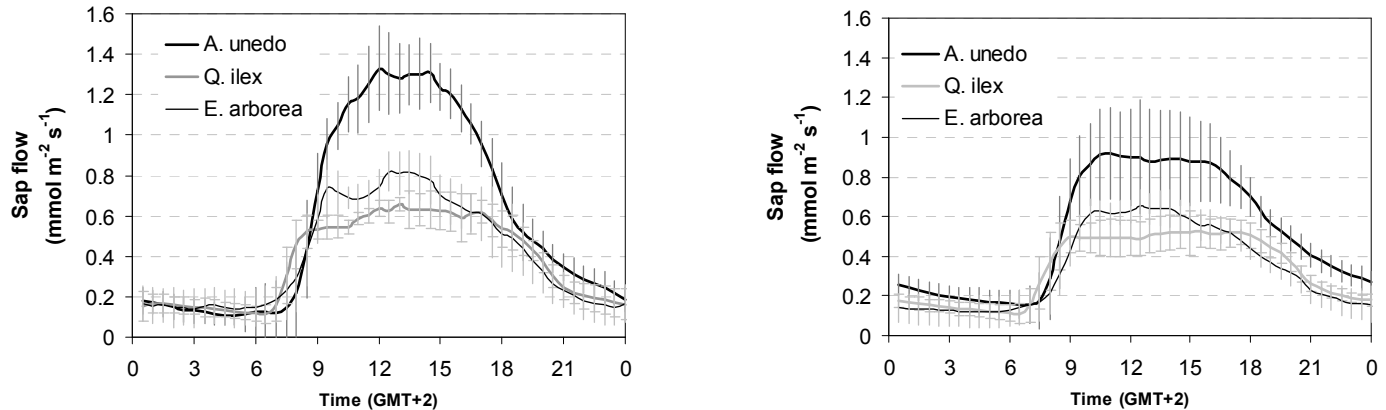

Fig. 11. Average days of sap flow for three species (A. unedo, Q. ilex, E. arborea). (a) mid May-12 June (b) 13th June-end July (data from Mereu et al., 2009). Vertical bars are the standard deviations.

stems and soil. The chemical process of ozone decomposition and reaction with air water vapour and droplets has been described by Seinfeld and Pandis (1998) and de Paula and Atkins (2006). Nevertheless, the proximity of the coastline could bring to suppose a contribution of marine aerosols which can modify the chemical properties of the water films and consequently enhance ozone solubility and its removal. Recent findings on the chemistry of halogen compounds $(\mathrm{Br}$, $\mathrm{I}, \mathrm{Cl}$ ) in marine boundary layers MBL (Monks, 2005), suggest a possible role of these gas compounds in the removal of ozone in our coastal site. In fact, bromine and chlorine in the MBL are emitted through the production of sea salt aerosol, with a smaller fraction released from biogenic organic halogens. Iodine compounds on the other hand are largely released as organic compounds and molecular iodine from micro and macro algae that accumulate iodine from the sea water (von Glasow, 2008). Chemical and photochemical reactions rapidly convert these compounds in halogenated monoxides (Monks, 2005). These latter compounds are directly responsible for the catalytic removal through one prin- cipal and simple mechanism (von Glasow et al., 2002):

$$
\begin{aligned}
& \mathrm{XO}+\mathrm{YO} \rightarrow \mathrm{X}+\mathrm{Y}+\mathrm{O}_{2} \text { with } \mathrm{X} \text { and } \mathrm{Y}=\mathrm{Br}, \mathrm{I}, \mathrm{Cl} \\
& \mathrm{X}+\mathrm{O}_{3} \rightarrow \mathrm{XO}+\mathrm{O}_{2}
\end{aligned}
$$

Model calculations have indicated that the presence of only 0.5-4 $\mathrm{pmol} \mathrm{mol}^{-1} \mathrm{BrO}$ can significantly impact the $\mathrm{O}_{3}$ budget in the MBL by means of reactions that take place in the air (von Glasow et al., 2002; von Glasow and Crutzen, 2004).

Recently, BrO and IO measurements in Green Cape, not only confirmed the occurrence of such mechanism but also brought to the conclusion that the ozone photochemistry is largely dominated by halogen chemistry (Read et al., 2008). Interestingly, the daily profile reported for $\mathrm{BrO}$ and $\mathrm{IO}$ concentrations is similar to the ozone deposition found in this study. Concentrations of both gasses reach a maximum around 10 a.m., remain constant until 14 p.m. for IO and until 7 p.m. for $\mathrm{BrO}$, and decrease to 0 afterwards. In the coastal site subject to a considerable external source of $\mathrm{NO}_{\mathrm{x}}$ at night, as in this case, the formation of halogenated nitrates- as $\mathrm{BrONO}_{2}$ - can take place. At sunrise, these compounds photolyse freeing $\mathrm{NO}_{2}$ and halogenated oxides that may trigger 
a)

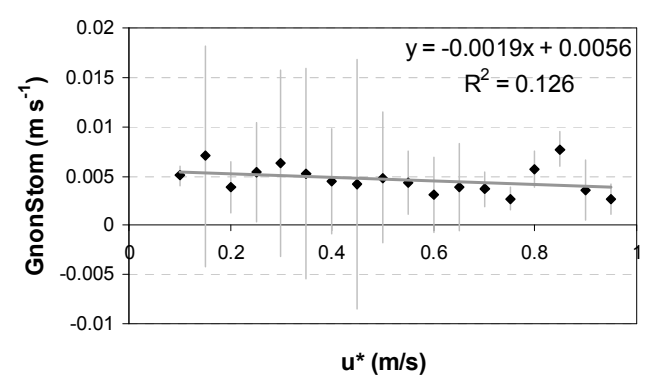

c)

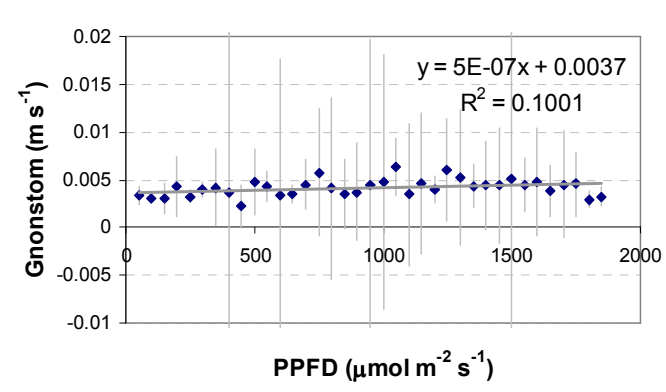

e)

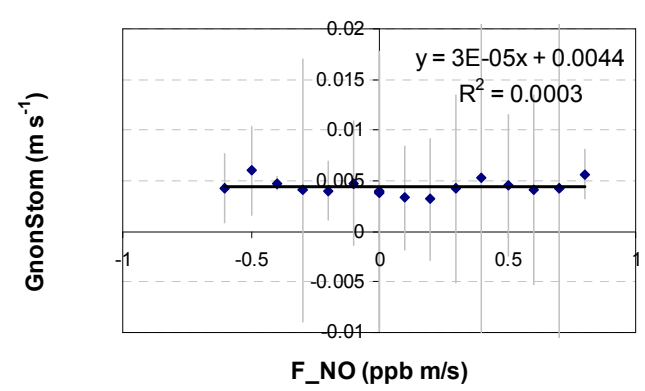

b)

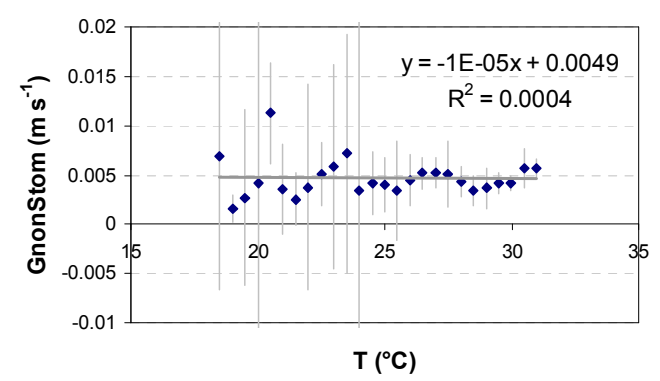

d)

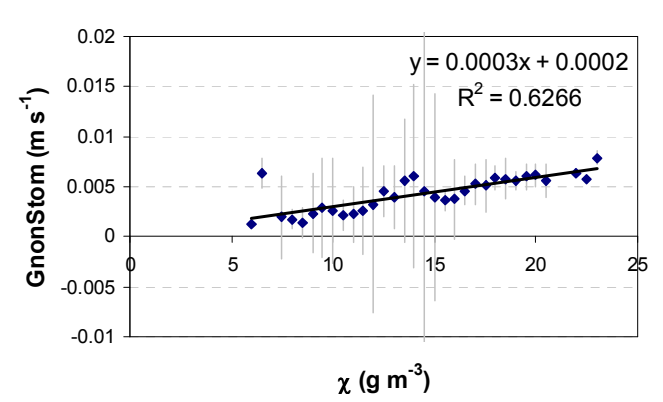

f)

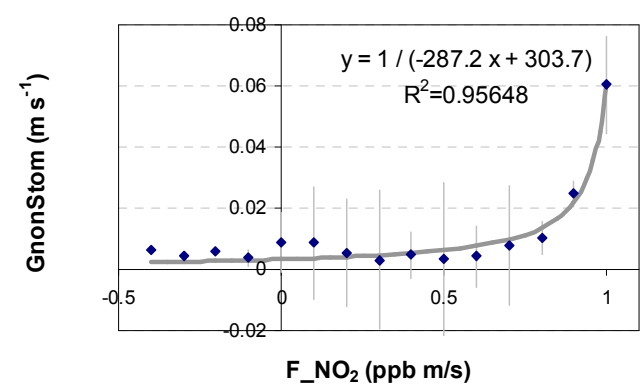

Fig. 12. Non-stomatal deposition $\left(G_{\text {nonStom }}\right)$ versus air turbulence $\left(u^{*}\right)$, air temperature $(T)$, solar radiation $(\mathrm{PPFD})$ and absolute air humidity $(\chi)$, NO and $\mathrm{NO}_{2}$ fluxes $\left(\mathrm{F} \_\mathrm{NO}\right.$ and $\left.\mathrm{F}_{-} \mathrm{NO}_{2}\right)$. Points are median values of non-stomatal conductance for each bin of the variable in $\mathrm{x}$-axis and vertical bars represent standard deviations. Note than the $\mathrm{y}$-axis in the $\mathrm{F} \_\mathrm{NO}_{2}$ graph has a different scale. Positive flux values indicate efflux and negative values depositions. Data from the whole measuring period have been considered.

and amplify the catalytic destruction of ozone. Such a process is what is suggested by the so-called "sunrise ozone destruction" reported by different authors (Nagao et al., 1999; Galbally et al., 2000; Watanabe et al., 2005). Such a morning peak of ozone depletion was already reported for a close site (Gerosa et al., 2005, 2009) and it occurred again during this campaign. The morning peak, especially in the first period, can be inferred from Figs. 2 and 6, where a rise in total ozone deposition is not supported by a concomitant rise in ozone stomatal uptake. This hypothesis would also explain the $\mathrm{NO}_{2}$ efflux in excess observed in the maquis during the day. In fact, the air masses of the city plume rich in nitrate species, would first be transported offshore from the night breeze and return to land during the day under the form of organic and halogenated nitrous compounds. Hence, if the hypothesis of the role of the chemistry of halogenated compounds should be confirmed also for this site, the correlation found with humidity could simply be an indicator of the transport of halogenated species from the sea when the wind was blowing from offshore. 
a)

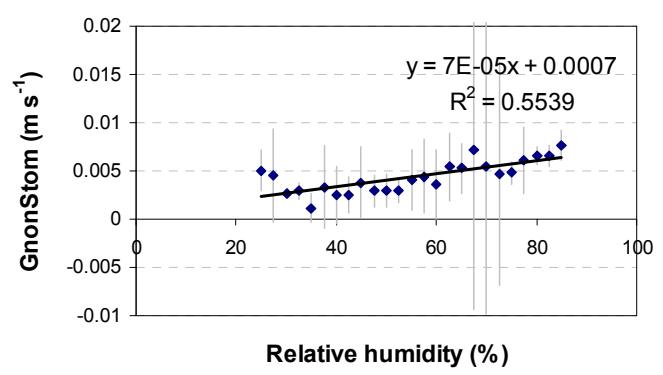

b)

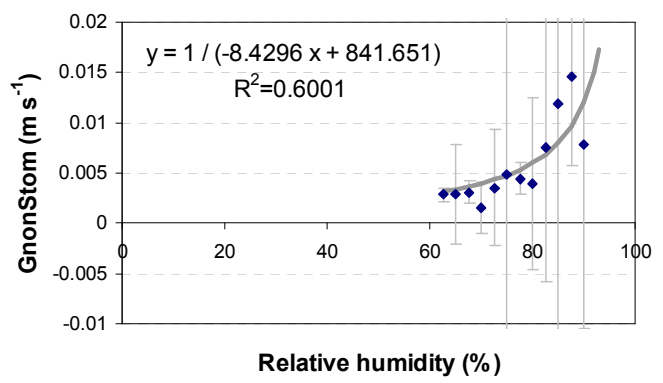

Fig. 13. Non-stomatal deposition and relative air humidity in (a) dry canopy and (b) wet canopy conditions. Vertical bars are the standard deviations. Data from the whole measuring period have been considered.

\subsection{Ozone risk assessment}

Ozone exposure was calculated as AOT40 using ozone concentrations both at the measuring point and at canopy level, calculating the latter ones by means of the DDIM.

In both cases the ozone exposure exceeded the critical level (CL) of $5000 \mathrm{ppb}$ h established for plants protection, revealing a potentially ozone hazard condition for the maquis ecosystem. Considering that the vegetative period of maquis is much longer than our measuring period, it can be reasonably supposed that the exposure to which these ecosystems are usually subject to is very high.

It is worth noticing that the CL was exceeded very soon by the AOT40 evaluated at the measuring height (23 May), and only one month and half later ( 5 July) at the canopy height $d+z_{0}$. The two metrics gave very different results, highlighting the importance of following the indications of the Mapping Manual (ICP Modelling and Mapping, 2004), the disrespect of which may bring to considerable overestimation of the risks - a three fold higher in this case - and to erroneous conclusions. The risk of overestimating the negative effects of ozone on the vegetation is particularly high in the Mediterranean area, where the concentrations of this pollutant are usually high (Paoletti, 2006).

The failure to estimate ozone concentrations at top canopy height is not necessarily due to negligence, but to the lack of the necessary information to infer the ozone gradient above the canopy when using data from monitoring network stations, which usually sample at a height of $3 \mathrm{~m}$. The determination of such gradient, in fact, requires knowledge of the aerodynamic state of the atmospheric surface layer (turbulence/stability) and the conductance to ozone of the ecosystem, which is known to vary rapidly as a response to the environmental conditions and to the physiological state of the plant. Ultimately, ozone exposure at top canopy height can be determined only through direct flux measurements. Measurements that, as in this case, can be more profitably used to determine the stomatal ozone uptake, one of the most sig- nificant toxicological parameters. However, it must be noticed that the phytotoxical part of ozone taken up by plants could be reduced by meshopyll reactions between ozone and monoterpens; quantification of the detoxification process has still some uncertainties but this process could explain the high resistance of Mediterranean species to the ozone.

The dose of ozone absorbed by the vegetation during the measuring period, appears well above the provisional critical flux level of $4 \mathrm{mmol} \mathrm{m}^{-2}$, expressed as $\mathrm{AF}_{s t} 1.6$, for the reduction of $5 \%$ of biomass growing in beech and birch (ICP Modelling and Mapping, 2004; Karlsson et al., 2004)

This dose, however, is below the critical dose for the appearance of visible injury symptoms on leaves $\left(30 \mathrm{mmol} \mathrm{m}^{-2}\right)$ of beech and poplar found in recent OTC experiments (Gerosa et al., 2009b). These experiments reported also that even at lower doses, even asymptomatic species such as $Q$. robur, when exposed to ozone, showed a marked reduction in the photosynthetic efficiency over a long period (Bussotti et al., 2007). Hence, even if direct assimilation measurements by Fares et al. (2009) in the first measuring period did not show an assimilation reduction and no leaf injuries were observed in this study, it cannot be a priori excluded that photosynthetic assimilation was negatively influenced by ozone over the whole measuring period ( 5 June to 31 July 2007) and ozone activated antioxidant systems capable of protecting the vegetation from photo-oxidative stress (Nali et al., 2004; Paoletti, 2006).

In any case, in a multi specific ecosystem the ozone risk assessment might to be more precise and take into account the specific physiology of each species. Some species, in fact, can largely account for the dose of ozone absorbed by the ecosystem and hence may be relatively more affected by this pollutant and trigger future changes in ecosystem composition. This is what happened, for example, for the three species $A$. unedo, $Q$. ilex, E. arborea considered in the Fig. 11, which shows different values of stomatal conductance for each species and hence each one absorbed a different ozone dose. 
Finally, the measured dose is very close to the $24 \mathrm{mmol} \mathrm{m}^{-2}$ estimated for forests, in the same area and for the year 2000, by the renovated deposition module $\mathrm{DO}_{3} \mathrm{SE}-$ EMEP (Simpson et al., 2007). But it should be noted that the model estimation covered 6 months of the entire growing season and not only the central three months, as in our case.

In any case model parameterizations for this ecosystem are still necessary.

\section{Conclusions}

The maquis ecosystem acted as a net sink for ozone and the ozone deposition was quite high. Nevertheless, only a minor part of the ozone flux (32.8\%) was absorbed by vegetation through the stomata. The stomatal uptake was influenced by water availability and decreased throughout the measuring period as the season became dryer.

The remaining part of the ozone deposition, the so called non-stomatal one, was positively influenced by air humidity and by nitrogen oxides. Nevertheless the influence of these latter was weak, and was evident only when nitrogen fluxes were particularly high. No influence with other measured factors, such as temperature, solar radiation and turbulence intensity were found. Moreover, due to the coastal location of the measuring site, a possible role on ozone depletion of halogenated species advected from the sea was also suggested as a working hypothesis, even if it should be confirmed by new measurements.

The maquis ecosystem resulted at high risk for ozone considering both AOT40 and $\mathrm{AF}_{s t} 1.6$ approaches, just on a three months base instead of six months as suggested by UN-ECE. Hence, negative effects on the vegetation community cannot be excluded for this particular ecosystem, and more in general for the Mediterranean maquis ecosystems. However the different behaviors shown by the exposure and the dose metrics highlighted the need for field measurements in order to realize a better risk assessment.

Finally a significant dataset is now available in ASCII format for testing, refining and validating deposition models on this type of ecosystems and Mediterranean climatic conditions.

Acknowledgements. The field campaign was supported by the VOCBAS and ACCENT/BIAFLUX programs. We're also grateful to the Exchange of Staff funding Program of the ACCENT/BIAFLUX Network of Excellence for its support.

A special thank to the Scientific Committee of the Presidential Estate of Castelporziano and to its staff who allowed this work.

Edited by: F. Loreto

\section{References}

Altimir, N., Tuovinen, J., Vesala, T., Kulmala, M., and Hari, P.: Measurements of ozone removal by Scots pine shoots: calibra- tion of a stomatal uptake model including the non-stomatal component, Atmos. Environ., 38, 2387-2398, 2004.

Altimir, N., Kolari, P., Tuovinen, J.-P., Vesala, T., Bäck, J., Suni, T., Kulmala, M., and Hari, P.: Foliage surface ozone deposition: a role for surface moisture?, Biogeosciences, 3, 209-228, 2006, http://www.biogeosciences.net/3/209/2006/.

Ashmore, M., Büker, P., Emberson, L., Terry, A. C., and Toet, S.: Modelling stomatal ozone flux and deposition to grassland communities across Europe, Environ. Pollut., 146, 659-670, 2007.

Benton, J., Fuhrer, J., Gimeno, B. S., Skärby, L., Palmer-Brown, D., Ball, G. R., Roadknight, C., and Mills, G.: An international cooperative programme indicates the widespread occurrence of ozone injury on crops, Agric., Ecosyst. Env., 78, 19-30, 2000.

Bermejo, V., Gimeno, B. S., Sanz, M. J., De La Torre, D., and Gil, J. M.: Assessment of the ozone sensitivity of 22 native plant species from Mediterranean annual pastures based on visible injury, Atmos. Environ., 37, 4667-4677, 2003.

Bombelli, A. and Gratani, L.: Interspecific Differences of Leaf Gas Exchange and Water Relations of Three Evergreen Mediterranean Shrub Species, Photosynthetica, 41, 619-625, 2003.

Bussotti, F. and Gerosa, G.: Are the Mediterranean forests in Southern Europe threatened from ozone?, J. Medit. Ecol., 3, 23-34, 2002.

Bussotti, F., Cozzi, A., and Ferretti, M.: Field Surveys of Ozone Symptoms on Spontaneous Vegetation. Limitations and Potentialities of the European programme, Environ. Monit. Assess., 115, 335-348, 2006.

Bussotti, F., Desotgiu, R., Cascio, C., Strasser, R. J., Gerosa, G., and Marzuoli, R.: Photosynthesis responses to ozone in young trees of three species with different sensitivities, in a 2-year opentop chamber experiment (Curno, Italy), Physiologia Plant., 130, 122-135, 2007.

Cieslik, S.: Ozone fluxes over various plant ecosystems in Italy: A review, Environ. Pollut., 157, 1487-1496, 2009a

Cieslik, S. A., Gerosa, G., Finco, A., Matteucci, G., Cape, N., and Misztal, P.: Turbulence in a coastal Mediterranean area: surface fluxes and related parameters at Castel Porziano, Italy, Biogeosciences Discuss., 6, 3355-3372, 2009b, http://www.biogeosciences-discuss.net/6/3355/2009/.

Clary, J., Save, R., Biel, C., and Herralde, F.: Water relations in competitive interactions of Mediterranean grasses and shrubs, Ann. Appl. Biol., 144, 149-155, 2004.

Coe, H., Gallagher, M., Choularton, T., and Dore, C.: Canopy scale measurements of stomatal and cuticular $\mathrm{O} \sim 3$ uptake by Sitka Spruce, Atmos. Environ., 29, 1413-1413, 1995.

De Paula, J. and Atkins, P.: Explorations in Physical Chemistry, Oxford University Press, 2006.

Dorsey, J. R., Duyzer, J. H., Gallagher, M. W., Coe, H., Pilegaard, K., Weststrate, J. H., Jensen, N. O., and Walton, S.: Oxidized nitrogen and ozone interaction with forests. I: Experimental observations and analysis of exchange with Douglas fir, Q. J. Roy. Meteor. Soc., 130, 1941-1955, 2004.

Dutaur, L., Carrara, S., and Lopez, A.: The detection of nonstationarity in the determination of deposition fluxes, Proceedings of EUROTRAC Symposium'98, 171-176, 1999.

Duyzer, J., Weststrate, H., and Walton, S.: Exchange of ozone and nitrogen oxides between the atmosphere and coniferous forest, Water, Air, Soil Pollut., 85, 2065-2070, 1995.

Fay, J. A. and Hoult, D. P.: Akademija Nauk CCCP, Leningrad, 
Trudy Geofizicheskowo Instituta, 151(24), 163-187, 1954.

Elvira, S., Bermejo, V., Manrique, E., and Gimeno, B. S.: On the response of two populations of Quercus coccifera to ozone and its relationship with ozone uptake, Atmos. Environ., 38, 23052311, 2004.

Emberson, L. D., Massman, W. J., Büker, P., Soja, G., van de Sand, I., Mills, G., and Jacobs, C.: The development, evaluation and application of $\mathrm{O}_{3}$ flux and flux-response models for additional agricultural crops, Critical Levels for Ozone: Further Applying and Developing the Flux-based Concept, Innsbruck, Austria, 2005.

Emberson, L., Büker, P., and Ashmore, M.: Assessing the risk caused by ground level ozone to European forest trees: A case study in pine, beech and oak across different climate regions, Environ. Pollut., 147, 454-466, 2007.

Fares, S., Mereu, S., Scarascia Mugnozza, G., Vitale, M., Manes, F., Frattoni, M., Ciccioli, P., Gerosa, G., and Loreto, F.: The ACCENT-VOCBAS field campaign on biosphere-atmosphere interactions in a Mediterranean ecosystem of Castelporziano (Rome): site characteristics, climatic and meteorological conditions, and eco-physiology of vegetation, Biogeosciences, 6, 1043-1058, 2009, http://www.biogeosciences.net/6/1043/2009/.

Felzer, B., Kicklighter, D., Melillo, J., Wang, C., Zhuang, Q., and Prinn, R.: Effects of ozone on net primary production and carbon sequestration in the conterminous United States using a biogeochemistry model, Tellus B, 56, 230-248, 2004.

Foken, T.: Micrometeorology, Springer-Verlag, Berlin Heidelberg, ISBN: 978-3-540-74665-2, 308 pp., 2008.

Fowler, D., Flechard, C., Cape, J. N., Storeton-West, R. L., and Coyle, M.: Measurements of Ozone Deposition to Vegetation Quantifying the Flux, the Stomatal and Non-Stomatal Components, Water, Air, Soil Pollut., 130, 63-74, 2001.

Galbally, I. E., Bentley, S. T., and Meyer, C. P. M.: Mid-latitude marine boundary-layer ozone destruction at visible sunrise observed at Cape Grim, Tasmania, 41 S, Geophys. Res. Lett, 27, 3841-3844, 2000.

Gao, W., Wesely, M., and Doskey, P.: Numerical modeling of the turbulent diffusion and chemistry of $\mathrm{NO}_{\mathrm{x}}, \mathrm{O}_{3}$, isoprene, and other reactive trace gases in and above a forest canopy, J. Geophys. Res., 98, 18339-18354, 1993.

Gerosa, G., Cieslik, S., and Ballarin-Denti, A.: Micrometeorological determination of time-integrated stomatal ozone fluxes over wheat: a case study in Northern Italy, Atmos. Environ., 37, 777788, 2003

Gerosa, G., Finco, A., Mereu, S., Vitale, M., Manes, F., and Ballarin Denti, A.: Comparison of seasonal variations of ozone exposure and fluxes in a Mediterranean Holm oak forest between the exceptionally dry 2003 and the following year, Environ. Pollut., 157, 1737-1744, 2009a.

Gerosa, G., Marzuoli, R., Cieslik, S., and Ballarin-Denti, A.: Stomatal ozone fluxes over a barley field in Italy."Effective exposure" as a possible link between exposure-and flux-based approaches, Atmos. Environ., 38, 2421-2432, 2004.

Gerosa, G., Marzuoli, R., Desotgiu, R., Bussotti, F., and BallarinDenti, A,: Validation of the stomatal flux approach for the assessment of ozone effects on young forest trees, A summary report of the TOP (Transboundary Ozone Pollution) experiment at Curno, Italy. Environ. Pollut., 157, 1497-1505, 2009b
Gerosa, G., Vitale, M., Finco, A., Manes, F., Ballarin-Denti, A., and Cieslik, S. A.: Ozone uptake by an evergreen Mediterranean Forest (Quercus ilex) in Italy, Part I: Micrometeorological ?ux measurements and ?ux partitioning, Atmos. Environ., 39, 32553266, 2005.

Grünhage, L., Haenel, H., and Jäger, H.: The exchange of ozone between vegetation and atmosphere: micrometeorological measurement techniques and models, Environ. Pollut., 109, 373-392, 2000 .

Hicks, B. B. and Matt, D. R.: Combining biology, chemistry, and meteorology in modeling and measuring dry deposition, J. Atmos. Chem., 6, 117-131, 1988.

Hicks, B., Baldocchi, D., Meyers, T., Hosker, R., and Matt, D.: A preliminary multiple resistance routine for deriving dry deposition velocities from measured quantities, Water, Air, Soil Pollut., 36, 311-330, 1987.

ICP Modelling and Mapping.: Manual on Methodologies and Criteria for Modelling and Mapping Critical Loads and Levels and Air Pollution Effects, Risks and Trends. Federal Environmental Agency (Umweltbundesamt),Berlin. UBA-Texte52/04, available from: www.icpmapping.org, 2004.

Kaimal, J. and Finnigan, J.: Atmospheric Boundary Layer Flows: Their Structure and Measurement, Oxford University Press, USA, 1994.

Karlsson, P. E., Braun, S., Broadmeadow, M., Elvira, S., Emberson, L., Gimeno, B., Thiec, D. L., Novak, K., Oksanen, E., Schaub, M., Uddling, J., and Wilkinson, M.: Risk assessments for forest trees: The performance of the ozone flux versus the AOT concepts, Environ. Pollut., 146, 608-616, 2007.

Karlsson, P., Uddling, J., Braun, S., Broadmeadow, M., Elvira, S., Gimeno, B., Le Thiec, D., Oksanen, E., Vandermeiren, K., and Wilkinson, M.: New critical levels for ozone effects on young trees based on AOT40 and simulated cumulative leaf uptake of ozone, Atmos. Environ., 38, 2283-2294, 2004.

Keronen, P., Reissell, A., Rannik, U., Pohja, T., Siivola, E., Hiltunen, V., Hari, P., Kulmala, M., and Vesala, T.: Ozone flux measurements over a Scots pine forest using eddy covariance method: performance evaluation and comparison with fluxprofile method, Boreal Env. Res., 8, 425-444, 2003.

King, J. S., Kubiske, M. E., Pregitzer, K. S., Hendrey, G. R., McDonald, E. P., Giardina, C. P., Quinn, V. S., and Karnosky, D. F.: Tropospheric $\mathrm{O} 3$ compromises net primary production in young stands of trembling aspen, paper birch and sugar maple in response to elevated atmospheric $\mathrm{CO}_{2}$, New Phytologist, 168, 623636, 2005.

Kurpius, M. and Goldstein, A.: Gas-phase chemistry dominates $\mathrm{O}_{3}$ loss to a forest, implying a source of aerosols and hydroxyl radicals to the atmosphere, Geophys. Res. Lett., 30, 1371, doi:10.1029/2002GL016785, 2003.

Loreto, F. and Fares, S.,: Is ozone flux inside leaves only a damage indicator? Clues from volatile isoprenoid studies, Plant Physiol., 143, 1096-1100, 2007.

Marzuoli, R., Gerosa, G., Desotgiu, R., Bussotti, F., and BallarinDenti, A.: Ozone fluxes and foliar injury development in the ozone-sensitive poplar clone Oxford (Populus maximowiczii $\mathrm{x}$ Populus berolinensis): a dose-response analysis, Tree Physiol., 29(1), 67-76, doi:10.1093/treephys/tpn012, 2008.

Massman, W.J.: A review of the molecular diffusivities of $\mathrm{H}_{2} \mathrm{O}$, $\mathrm{CO}_{2}, \mathrm{CH}_{4}, \mathrm{CO}, \mathrm{O}_{3}, \mathrm{SO}_{2}, \mathrm{NH}_{3}, \mathrm{~N}_{2} \mathrm{O}, \mathrm{NO}$, and $\mathrm{NO}_{2}$ in air, $\mathrm{O}_{2}$ 
and $\mathrm{N}_{2}$ near STP., Atmos. Environ., 32, 1111-1127, 1998.

Matyssek, R., Bytnerowicz, A., Karlsson, P. E., Paoletti, E., Sanz, M. J., Schaub, M., and Wieser, G.: Promoting the $\mathrm{O}_{3}$ flux concept for European forest trees, Environ. Pollut., 146, 587-607, 2007.

McMillen, R.: An eddy correlation technique with extended applicability to non-simple terrain, Bound.-Lay. Meteorol., 43, 231245, 1988.

Mereu, S., Salvatori, E., Fusaro, L., Gerosa, G., Muys, B., and Manes, F.: A whole plant approach to evaluate the water use of mediterranean maquis species in a coastal dune ecosystem, Biogeosciences Discuss., 6, 1713-1746, 2009, http://www.biogeosciences-discuss.net/6/1713/2009/.

Mikkelsen, T. N., Ro-Poulsen, H., Pilegaard, K., Hovmand, M. F., Jensen, N. O., Christensen, C. S., and Hummelshoej, P.: Ozone uptake by an evergreen forest canopy: temporal variation and possible mechanisms, Environ. Pollut., 109, 423-429, 2000.

Monin, A. S. and Obukhov, A. M.: Basic laws of turbulent mixing in the surface layer of the atmosphere, Contrib. Geophys. Inst. Acad. Sci. USSR, 151, 163-187, 1954.

Monks, P. S.: Gas-phase radical chemistry in the troposphere, Chemical Society Reviews, 34, 376-395, 2005.

Monson, R. and Holland, E.: Biospheric trace gas fluxes and their control over tropospheric chemistry, Ann. Rev. Ecol. Syst., 32, 547-576, 2001.

Monteith, J. and Unsworth, M.: Principles of Environmental Physics, 291 pp., Edward Arnold, London, 1990.

Monteith, J.: Evaporation and surface temperature, Q. J. Roy. Meteor. Soc., 107, 1-27, 1981.

Musselman, R. C., Lefohn, A. S., Massman, W. J., and Heath, R. L.: A critical review and analysis of the use of exposure-and fluxbased ozone indices for predicting vegetation effects, Atmos. Environ., 40, 1869-1888, 2006.

Nagao, I., Matsumoto, K., and Tanaka, H.: Sunrise ozone destruction found in the sub-tropical marine boundary layer, Geophys. Res. Lett., 26, 3377-3380, 1999.

Nali, C., Paoletti, E., Marabottini, R., Della Rocca, G., Lorenzini, G., Paolacci, A. R., Ciaffi, M., and Badiani, M.: Ecophysiological and biochemical strategies of response to ozone in Mediterranean evergreen broadleaf species, Atmos. Environ., 38, $2247-$ 2257, 2004.

Novak, K., Schaub, M., Fuhrer, J., Skelly, J., and Frey, B.: Ozone effects on visible foliar injury and growth of Fagus sylvatica and Viburnum lantana seedlings grown in monocolture $r$ in mixture, Environ. Exp. Bot., 62, 212-220, 2008.

Pal Arya, S.: Introduction to micrometeorology. Academic Press Inc., San Diego, California, 303 pp., 1988.

Paoletti, E.: Impact of ozone on Mediterranean forests: A review, Environ. Pollut., 144, 463-474, 2006.

Pilegaard, K., Hummelshoj, P., and Jensen, N. O.: Nitric oxide emission from a Norway spruce forest floor, J. Geophys. Res., 104(D3), 3433-3445, 1999.

Pilegaard, K.: Air-Soil Exchange of $\mathrm{NO}, \mathrm{NO}_{2}$ and $\mathrm{O}_{3}$ in Forests, Water, Air, Soil Pollut. Focus, 1, 79-88, 2001.

Pleijel, H., Danielsson, H., Ojanperä, K., De Temmerman, L., Högy, P., Badiani, M., and Karlsson, P. E.: Relationships between ozone exposure and yield loss in European wheat and potato a comparison of concentration- and flux-based exposure indices, Atmos. Environ., 38, 2259-2269, 2004.
Read, K., Mahajan, A., Carpenter, L., Evans, M., Faria, B., Heard, D., Hopkins, J., Lee, J., Moller, S., and Lewis, A.: Extensive halogen-mediated ozone destruction over the tropical Atlantic Ocean, Nature, 453, 1232-1235, doi:10.1038/nature07035, 2008.

Rondón, A.: Photoinduced deposition of ozone on the plant leaf cuticle. In "Atmosphere-surface exchange of nitrogen oxides and ozone", PhD thesis, Department of Meteorology, Stockholm University, 1993.

Seinfeld, J. and Pandis, S.: Atmospheric Chemistry and Physics: From Air Pollution to Climate Change, John Wiley \& Sons, Inc., New York, USA, 1998.

Simpson, D., Ashmore, M., Emberson, L., and Tuovinen, J. P.: A comparison of two different approaches for mapping potential ozone damage to vegetation, A model study, Environ. Pollut., 146, 715-725, 2007.

Skärby, L., Ro-Poulsen, H., AM Wellburn, F., and Sheppard, L. J.: Impacts of ozone on forests: a European perspective, New Phytologist, 139, 109-122, 1998.

Stull, R.: An Introduction to Boundary Layer Meteorology, Springer, 1988.

Swinbank, W. C.: The measurement of vertical transfer of heat and water vapor by eddies in the lower atmosphere, J. Atmos. Sci., 8 , 135-145, 1951.

Tuovinen, J. P., Ashmore, M. R., Emberson, L. D., and Simpson, D.: Testing and improving the EMEP ozone deposition module, Atmos. Environ., 38, 2373-2385, 2004.

Tuovinen, J. P., Simpson, D., Mikkelsen, T. N., Emberson, L. D., Ashmore, M. R., Aurela, M., Cambridge, H. M., Hovmand, M. F., Jensen, N. O., and Laurila, T.: Comparisons of Measured and Modelled Ozone Deposition to Forests in Northern Europe, Water, Air, Soil Pollut. Focus, 1, 263-274, 2001.

van der Hoven, I.: Power spectrum of horizontal wind speed in the frequency range from 0.0007 to 900 cycles per hour, J. Atmos. Sci., 14, 160-164, 1957.

van Pul, W. and Jacobs, A.: The conductance of a maize crop and the underlying soil to ozone under various environmental conditions, Bound.-Lay. Meteorol., 69, 83-99, 1994.

von Glasow, R. and Crutzen, P.: Model study of multiphase DMS oxidation with a focus on halogens, Atmos. Chem. Phys., 4, 589608, 2004,

http://www.atmos-chem-phys.net/4/589/2004/.

von Glasow, R., Sander, R., Bott, A., and Crutzen, P.: Modeling halogen chemistry in the marine boundary layer. 1. Cloud-free MBL, J. Geophys. Res., 107, 4341-4352, 2002.

von Glasow, R.: Tropospheric Halogen Chemistry. IGACtivities, Newsletter of the International Global Atmospheric Chemistry Project, 39, 2-10, 2008.

Walton, S., Gallagher, M. W., and Duyzer, J. H.: Use of a detailed model to study the exchange of $\mathrm{NOx}$ and $\mathrm{O} 3$ above and below a deciduous canopy, Atmos. Environ., 31, 2915-2931, 1997.

Watanabe, A., Nojiria, Y., and Kariyab, S.: Measurement on a commercial vessel of the ozone concentration in the marine boundary layer over the northern North Pacific Ocean, J. Geophys. Res., 110, D11310, doi:10.1029/2004JD005514, 2005.

Wesely, M. and Hicks, B.: A review of the current status of knowledge on dry deposition, Atmos. Environ., 34, 2261-2282, 2000. 